\title{
Erratum zu: Qualitative Inhaltsanalyse in naturwissenschaftsdidaktischer Forschung unter Berücksichtigung von Gütekriterien: Ein Review
}

\section{Maximilian Göhner ${ }^{1} \cdot$ Moritz Krell $^{1}$}

Online publiziert: 2. Juli 2021

() Der/die Autor(en) 2021

12

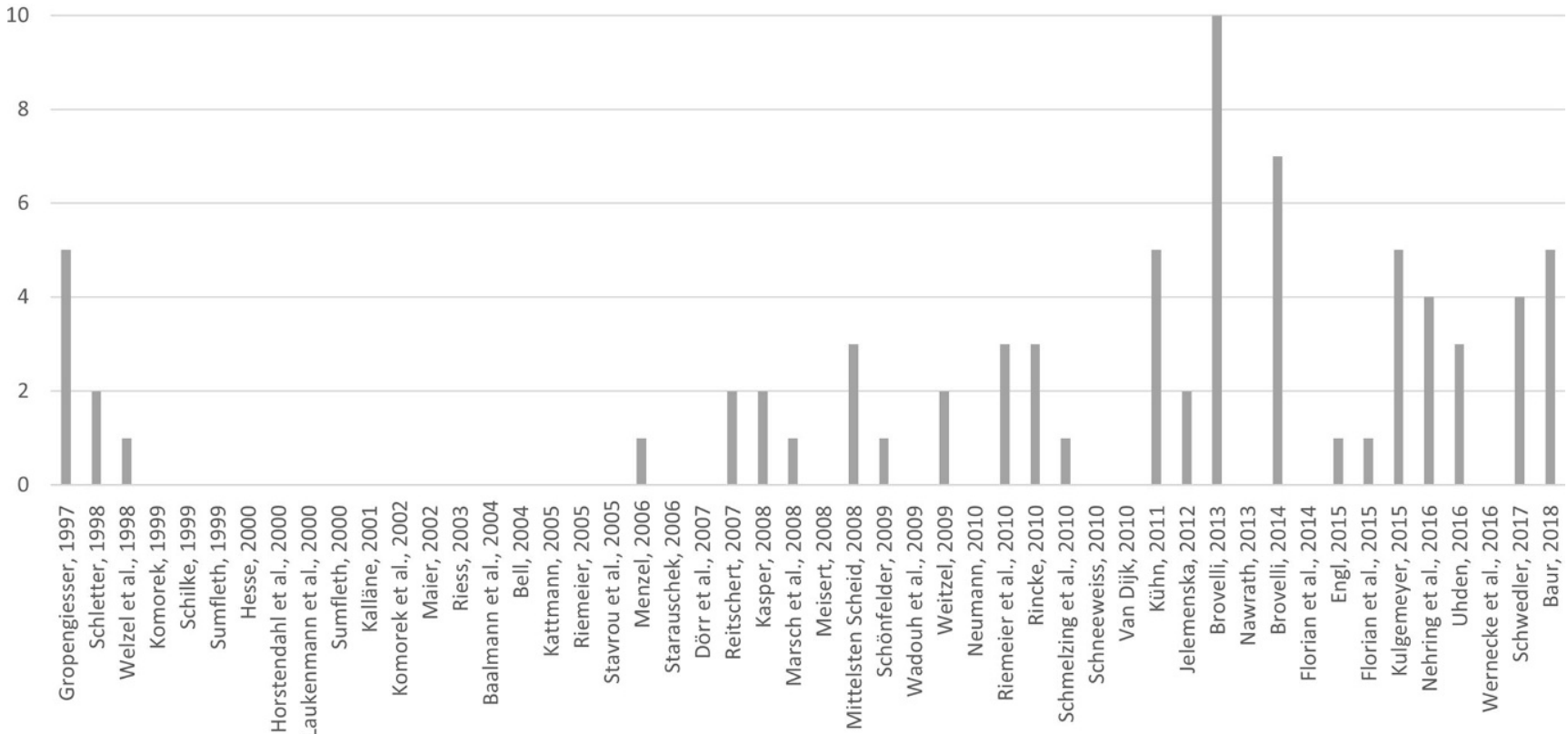

Abb. 2 Anzahl beschriebener Maßnahmen je untersuchtem Artikel, die einem Gütekriterium zugeordnet wurden

Erratum zu:

ZfDN 2020

https://doi.org/10.1007/s40573-020-00111-0

Die Online-Version des Originalartikels ist unter https://doi.org/ 10.1007/s40573-020-00111-0 zu finden.

Maximilian Göhner

maximilian.goehner@fu-berlin.de

1 Didaktik der Biologie, Freie Universität Berlin,

Schwendenerstraße 1, 14195 Berlin, Deutschland
In der Originalversion des Beitrags wurde in Abb. 2 ein Eintrag auf der $\mathrm{x}$-Achse nicht dargestellt, womit die Balken um einen Eintrag verschoben dargestellt wurden. Eine korrigierte Version der Abb. kann diesem Erratum entnommen werden.

Der Originalbeitrag wurde entsprechend geändert.

Open Access Dieser Artikel wird unter der Creative Commons Namensnennung 4.0 International Lizenz veröffentlicht, welche die Nutzung, Vervielfältigung, Bearbeitung, Verbreitung und Wiedergabe in jeglichem Medium und Format erlaubt, sofern Sie den/die ursprünglichen Autor(en) und die Quelle ordnungsgemäß nennen, einen Link 
zur Creative Commons Lizenz beifügen und angeben, ob Änderungen vorgenommen wurden.

Die in diesem Artikel enthaltenen Bilder und sonstiges Drittmaterial unterliegen ebenfalls der genannten Creative Commons Lizenz, sofern sich aus der Abbildungslegende nichts anderes ergibt. Sofern das betreffende Material nicht unter der genannten Creative Commons Lizenz steht und die betreffende Handlung nicht nach gesetzlichen Vorschriften erlaubt ist, ist für die oben aufgeführten Weiterverwendungen des Materials die Einwilligung des jeweiligen Rechteinhabers einzuholen.

Weitere Details zur Lizenz entnehmen Sie bitte der Lizenzinformation auf http://creativecommons.org/licenses/by/4.0/deed.de. 